OPEN ACCESS

Edited by:

Mirjam R. Heldner,

University Hospital Bern, Switzerland

Reviewed by: Marina Sorrentino Hernandes, Emory University, United States Theodoros Karapanayiotides, Aristotle University of Thessaloniki, Greece

*Correspondence: Håkon Ihle-Hansen haaih@vestreviken.no

Specialty section: This article was submitted to Stroke, a section of the journa Frontiers in Neurology

Received: 04 May 2021 Accepted: 30 June 2021 Published: 28 July 2021

Citation:

Ihle-Hansen $\mathrm{H}$, Ihle-Hansen $\mathrm{H}$, Sandset EC and Hagberg G (2021)

Subclinical Carotid Artery

Atherosclerosis and Cognitive

Function: A Mini-Review.

Front. Neurol. 12:705043

doi: 10.3389/fneur.2021.705043

\section{Subclinical Carotid Artery Atherosclerosis and Cognitive Function: A Mini-Review}

\author{
Håkon Ihle-Hansen ${ }^{1 *}$, Hege Ihle-Hansen ${ }^{1,2}$, Else Charlotte Sandset ${ }^{2}$ and Guri Hagberg 1,2 \\ ${ }^{1}$ Department of Medicine, Bærum Hospital- Vestre Viken Hospital Trust, Drammen, Norway, ${ }^{2}$ Oslo Stroke Unit, Department \\ of Neurology, Oslo University Hospital, Ullevål, Norway
}

Carotid artery atherosclerosis, the result of a multitude of vascular risk factors, is a promising marker for use in risk stratification. Recent evidence suggests that carotid artery atherosclerosis affects cognitive function and is an independent risk factor for the development of cognitive impairment. Both atherosclerosis and cognitive impairment develop over a prolonged period (years), and due to the aging population, markers to identify persons at risk are needed. Carotid artery atherosclerosis can easily be visualized using non-invasive ultrasound, potentially enabling early and intensified risk factor management to preserve cognitive function or delay further decline. However, the burden of atherosclerosis and temporal exposure required to pose a risk of cognitive impairment is unclear. This mini-review aims to explore the available evidence on the association between carotid atherosclerosis and cognition, and furthermore identify the remaining gaps in knowledge.

Keywords: IMT, cognitive function, dementia, plaque, carotid artery atherosclerosis

\section{INTRODUCTION}

The prevention of cognitive impairment is one of the most significant challenges of our time with up to 10 million new cases each year (1). The consequences of underlying vascular risk factors such as hypertension increase the risk of both atherosclerosis and cognitive impairment. Monitoring and treating vascular risk factors mid-life is a promising strategy to prevent dementia later in life (2). Furthermore, the burden of atherosclerosis correlates to the underlying burden of vascular risk factors (3) and can be viewed as a surrogate marker of total vascular risk.

Vascular risk factors including atherosclerosis seem to contribute not only to vascular cognitive impairment, but also in the pathophysiology of Alzheimers disease (4). It has been proposed that there may be a convergence of mechanisms in vascular and neurodegenerative processes that cause impairments of cognition. These mechanisms are not yet fully elucidated, but most likely mediated through small vessel disease, endothelial dysfunction, silent ischemia, and reduced cerebral blood flow, which precedes neurodegeneration and amyloid accumulation (5).

Atherosclerosis represents a systemic multifactorial and inflammatory disease affecting the vascular bed (6). It develops gradually over years, first as a thickening of the vessel wall's innermost layer - the intima (7), this can either abate or progress into an atherosclerotic plaque and a vascular stenosis (8). Several studies have shown an independent association between atherosclerosis and 
increased risk of cognitive impairment $(9,10)$. Predilection sites for atherosclerosis are large and medium-sized arteries as well as areas where laminar blood flow is disturbed.

The carotid artery is ideally placed for ultrasound examination and assessment of atherosclerosis. Different types of angiography examinations are available but either demand more resources or are associated with radiation exposure, leaving ultrasound best suited for screening purposes. Atherosclerosis in the carotid arteries correlates with the presence of atherosclerosis in other vessels (11). Definitions of subclinical atherosclerotic disease in various studies include increased intima-media thickness (IMT), atherosclerotic plaques, and asymptomatic stenosis. Assessment of subclinical carotid artery atherosclerosis holds promise as a marker to identify persons at risk and those who may benefit from intensified risk factor management to prevent further progression of atherosclerosis and cognitive decline.

Symptomatic atherosclerosis in pre- and intra- cerebral vessels increases the risk of brain damage with an associated increased risk of cognitive impairment (12). However, the link between subclinical atherosclerosis (meaning nearly or completely asymptomatic) and cognitive function in stroke-free subjects is not as clear, the available evidence is mainly from large population-based cohort studies.

In this mini-review, focusing on subclinical atherosclerosis located in the carotid arteries, we aim to explore the currently available evidence on the association between carotid atherosclerosis and cognition. Furthermore, evaluate any potential progressive relationships, and identify the remaining gaps in knowledge.

\section{SUBCLINICAL CAROTID ATHEROSCLEROSIS AND COGNITION}

Several large population studies have assessed the association between atherosclerosis and cognitive function, 20,000 with cross sectional design and 50,000 with a longitudinal design with long term follow-up (up 20 years) between initial assessment of atherosclerosis and outcome, i.e., worsening in cognitive performance or dementia (13). The studies included in our mini-review are described in detail in Table $\mathbf{1}$.

Association between subclinical atherosclerosis and cognitive performance in subjects free of known cognitive impairment was explored in 8 studies with a cross sectional design (14-21). Seven cross-sectional studies have found an association between markers of atherosclerosis and cognitive function (14-16, 18-21).

Four studies found an association between greater IMT and reduced performance in some specific cognitive domains $(14,16,18,22)$. The majority of studies included subjects with more advanced atherosclerosis, i.e., plaque, plaque burden, and stenosis (14-16, 20,21), supporting the notion of an inverse association between increasing atherosclerotic burden and cognitive function.

Nine studies including a total of 23,000 patients showed associations between higher IMT and deterioration of cognitive performance over time $(9,13,23-30)$. On the other hand, the level of IMT was not associated with decreased cognitive performance in five studies including in total 27,000 patients (10, 31-34).

The location of the IMT measurement may be of importance. In the Framingham study, greater IMT in the internal carotid artery was associated with impaired cognitive function. However, no such association was found when assessing the common carotid intima-media thickness (ccIMT) and cognitive impairment (32).

Further, eight studies reported associations between carotid plaque/stenosis and decreasing cognitive performance and cognitive impairment in long-time follow-up $(10,13,27,30-33$, 35 ), and four studies showed that plaque/stenosis was superior to IMT at predicting cognitive decline $(10,31-33)$.

\section{DISCUSSION}

There is a significant association between different subclinical atherosclerosis measures and cognition in large population studies, both in studies with cross-sectional design and in longitudinal studies showing progressive changes over time.

The current evidence suggests a stronger association between cognitive impairment and more pronounced subclinical atherosclerosis. In the Cardiovascular Health Study and the Framingham study, asymptomatic $\geq 50 \%$ carotid artery stenosis (conventionally defined as significant atherosclerosis) predicted poorer cognitive performance $(10,32)$. Both studies failed to find an association between ccIMT and cognition.

Some studies reported no association between continuous measures of IMT and cognitive function, while as a dichotomized variables were significant (35). While increased IMT may represent non-atherosclerotic age-associated changes in the vessel wall, vessel wall tension, or an adaptive response to changes in flow, it is believed that IMT in the upper reference range is less likely to reflect these non-atherosclerotic processes.

Whether the location of atherosclerosis is relevant is still unclear. In the Framingham study, they found that IMT in the internal carotid artery (ICA), in contrast to ccIMT, was more associated with cognitive impairment (32). Atherosclerosis develops earlier in vessel bifurcations and origins such as the carotid bulb and proximal ICA which could explain associations between IMT and cognitive impairment in ICA, but not common carotid artery. However, atherosclerosis (including increased IMT) in other locations than the carotid arteries have also been associated with reduced cognition, supporting the hypothesis that atherosclerosis is a systemic disease of the vascular bed (36).

The exact pathophysiological mechanisms of atherosclerosisinduced cognitive impairment have not yet been identified. Population-based studies do not have the ideal design to illicit an answer and mechanisms may include cerebral changes resulting from silent embolization, inflammation or hypoperfusion (2, $37,38)$. Increased arterial stiffness leads to increased pulsewave velocity,pulsatile pressure and flow in the small vessels $(2,39)$, and a potential failure in the blood-brain barrier. Since the pathological mechanisms remain unknown, the possibility of reverse causality or that atherosclerosis and cognitive impairment develop in parallel cannot with certainty 
TABLE 1 | Excerpts from relevant populations-based studies.

\begin{tabular}{llll}
\hline $\begin{array}{l}\text { Author, journal, year } \\
\text { study }\end{array}$ & $\begin{array}{l}\text { Population size } \\
\text { and age }\end{array}$ & Measurements & $\begin{array}{l}\text { Observation } \\
\text { time }\end{array}$ \\
\hline $\begin{array}{l}\text { Gustavsson, Ann } \\
\text { Neurol 2020, Malmö } \\
\text { Diet and Cancer Study }\end{array}$ & $\begin{array}{l}\text { N 6,103, mean } \\
\text { age 57.5 }\end{array}$ & $\begin{array}{l}\text { Carotid plaques } \\
\text { and IMT }\end{array}$ & $\begin{array}{l}\text { 20 years } \\
(1991 / 1994-2014)\end{array}$ \\
$\begin{array}{l}\text { Wendel, Stroke 2009, } \\
\begin{array}{l}\text { Baltimore Longitudinal } \\
\text { Study of Aging }\end{array}\end{array}$ & $\begin{array}{l}\text { N 538, mean age } \\
\text { Van Oijen, Ann Neurol }\end{array}$ & cclMT & \\
$\begin{array}{l}\text { 2007, Rotterdam Study } \\
\text { age 72.4 }\end{array}$ & & $\begin{array}{l}\text { Up to11 years } \\
\text { (mean 4 years) }\end{array}$ \\
& & cclMT, carotid & mean 9.0 years \\
plaques & (1990/1993- \\
$1997 / 1999)$
\end{tabular}

Knopman, Neurology 2001, Atherosclerosis Risk in Communities cohort (ARIC)

Wendell, Stroke 2012, Baltimore Longitudinal Study of Aging

Arntzen, 2012,

Cerebrovasc Dis.

Tromsø Study

$\begin{array}{lll}\begin{array}{l}\text { N 10,963, age } \\ \text { range 47-70 }\end{array} & \begin{array}{l}\text { cclMT, divided into } \\ \text { tertiles (mean of } \\ \text { three sites } \\ \text { bilaterally) }\end{array} & \text { Mean 6 years } \\ & \text { IMT and carotid } & \text { Up to 14 years } \\ \text { N 364, age 60-95 } & \text { plaque } & (\text { mean } 6.7, \text { median } \\ \text { (mean 73.6, } & & 7,0)\end{array}$

N 4,371

$\mathrm{N} 348$, mean age 71.7

N 4,006 right-handed 65 years of age or older

N1,971 mean age, 58 years

ccIMT and Left Up to 5 years Internal carotid artery stenosis (> or $=75 \%$ narrowing of diameter)

cclMT and carotid Average of 4 years stenosis
Moon, Stroke 2015 , Korean Longitudina Study on Health and Aging

Johnston, Ann Intern Med 2004,

Cardiovascular Health Study

Romero, Stroke 2009, Framingham study
Sander, Geriatric Psychiatry 2009, INVADE study

N 2,693, mean cclMT 2 years

Outcome

Carotid plaques: Vascular Dementia

HR 1.90 [95\% Cl 1.07-3.38].

IMT: Dementia HR 1.14 [95\% C

1.03-1.26]; Vascular Dementia HR 1.32 [95\% Cl 1.10-1.57]

cclMT associated with decline in performance on multiple measures of verbal and nonverbal memory ccIMT in the fifth quintile compared with the first, and Carotid plaques in 5 or 6 locations compared with subjects without carotid plaques were predictor of dementia

ccIMT were not associated with change in cognitive test scores

\section{IMT: $>2.5$-fold increased risk of} dementia [HR $2.55(95 \% \mathrm{Cl}$ 1.32-4.96)] among individuals in the upper quintile of IMT.

Plaque: Approximately 2.0-fold increased risk of dementia [HR 1.98 (95\% Cl 1.06-3.70)] among individuals with bilateral plaque.

Plaques: Presence of plaques was significantly associated with change in cognitive test scores. The number of plaques and the total plaque area were associated with lower scores on the verbal memory test. ccIMT: No significant association was seen between ccIMT and cognitive test scores.

Plaque: not associated with cognitive decline after multiple adjustments. ccIMT: independent risk factor for the future progression of cognitive dysfunction [HR 1.251 (95\% Cl 1.006-1.555)].

Left internal carotid stenosis: Average decrease of more than 1 point annually in Modified Mini-Mental State Examination, OR, 6.7 (95\% Cl 2.4-18.1) compared with no stenosis. cc/MT left side was not associated with cognitive decline after adjustment.

Internal carotid stenosis $>50 \%$ : associated with poorer performance on executive function ( $\beta=-0.42 \pm$ SE 0.18; $P=0.02$ ) cCIMT: not associated with cognitive function

ccIMT: Significant higher C-IMT in those who developed cognitive decline compared to those who did not. (0.87 vs. $0.78 \mathrm{~mm} ; p<0.0001$ ).

\section{Adjusted for}

Cardiovascular risk factors, education, ApoE, age, sex

Age, sex, race, cardiovascular risk factors

Age and sex and cardiovascular factors

Cardiovascular risk factors, sex, race, education level, site, central nervous system medication and age

Cardiovascular risk factors, ApoE

Sex, age, education, depression and vascular risk factors

Hypertension, Cumulative Illness Rating Scale-Geriatric, depression, education and sex.

Right-sided stenosis

Age, sex, time to MRI/NP, diabetes, smoking, hypertension treatment, systolic blood pressure, and cardiovascular disease

Age, gender, prevalent ischemic heart disease, peripheral artery disease, hypertension, blood glucose, carotid plaques, education level, physical activity and the Geriatric Depression Scale 
TABLE 1 | Continued

\begin{tabular}{|c|c|c|c|c|c|}
\hline $\begin{array}{l}\text { Author, journal, year } \\
\text { study }\end{array}$ & $\begin{array}{l}\text { Population size } \\
\text { and age }\end{array}$ & Measurements & $\begin{array}{l}\text { Observation } \\
\text { time }\end{array}$ & Outcome & Adjusted for \\
\hline $\begin{array}{l}\text { Newman, JAGS 2005, } \\
\text { Cardiovascular Health } \\
\text { Study Cohort }\end{array}$ & $\begin{array}{l}\text { N 3,602, median } \\
\text { age } 74(65-97)\end{array}$ & $\begin{array}{l}\text { ccIMT, ilMT and } \\
\text { carotid stenosis }\end{array}$ & Mean 5,4 years & $\begin{array}{l}\text { cclMT and iMT: highest quartile } \\
\text { associated with increased risk of } \\
\text { dementia [HR1,6 (95\% Cl 1.1-2.2) vs. } \\
1,5 \text { (95\%Cl 1.1-2.0) respectively]. } \\
\text { Carotid stenosis: (regardless degree }\end{array}$ & $\begin{array}{l}\text { Age, race, education, income, } \\
\text { ApoE, and Modified } \\
\text { Mini-Mental State Examination } \\
\text { score at the time of the brain } \\
\text { magnetic resonance scan. }\end{array}$ \\
\hline
\end{tabular}

Zhong, Atherosclerosis 2012, Beaver Dam

Offspring Study

Carcaillon, Alzheimer's

Dementia 2015

Three-City Study

Gardener, 2017,

Stroke, Northern

Manhattan Study

Komulainen,

Neuroepidemiology

2007

Hsiu-Fen,

Atherosclerosis 2020,

Kaohsiung

Atherosclerosis

Longitudinal Study

(KALS)

Mathiesen, Neurology

2004, Tromsø study

Zhong, Atherosclerosis

2011, Beaver Dam

Ihle-Hansen, Journal of Alzheimer's Disease

2019, Cardiac

N 1,651, mean age 66.8

65-86 years

N 826, mean age

70 years

N 91 women, age

60-70

N 528, mean age

53.9 years

cclMT and

plaques

$N 189$ subjects with stenosis was compared to 201 control subjects mean age was 67.7 years

N 2,794, mean age 49 years (21-84)

N 3,413, mean age 63.9 years (63-65)

Examination 1950

Study

Auperin, Stroke 1996, EVA Study ( $\geq 35 \%)$

$\mathrm{N} 1,389$, mean age 65.0 (59-71)
ccIMT and

plaques
N 6,025, aged

IMT and plaque

Mean 9.2 years (range: 3-13 years)

of stenosis) not associated with dementia

IMT: associated with incidence of cognitive impairment [HR: 1.09, (95\% Cl: 1.01-1.18)] for each $0.1 \mathrm{~mm}$ increase in IMT.

Plaque: not associated with incident cognitive impairment or cognitive test performance 10 years later.

Plaque: Only plaque were independently related to Vascular or mixed dementia, HR $1.92[95 \% \mathrm{Cl}$ 1.13-3.22]

cclMT: Those with greater ccIMT exhibited worse cognitive performance. Carotid plaque not significantly with cognition at baseline or over time.

IMT: Increased IMT at baseline was an independent predictor for poorer cognitive performance

cclMT in the top quartile of and plaques were associated with low 10-year cognitive test scores

Carotid stenosis Cross-sectional

IMT and plaque

Cross sectiona

Carotid plaques

Cross sectiona
Carotid stenosis: associated with poorer neuropsychological performance

IMT and presence of plaque were associated with cognitive performance

Carotid plaque burden was in contrast to diameter [B - 0.17 (95\%

$-0.32-0.01)]$ or area $[\mathrm{B}-0.02(95 \%$ $-0.03-0.01)$ J of the thickest plaque not associated with cognitive performance

Cross sectional

Plaques: Poor cognitive functioning was associated with plaques. cCIMT: there was only a weak association in the subgroup of men with plaques. No association was found in women.
Age, sex, and education, cardiovascular risk factors and SF-36 mental health

Age, sex, ApoE, education, cardiovascular risk factors, personal history of coronary heart disease and stroke

Age, education, race and vascular risk factors

Age, education, depression, cardiovascular risk factors, cardiovascular disease, hormone replacement therapy, alcohol consumption and physical activity

Age, sex, educational status, diabetes, hypertension, hypercholesterolemia, and smoking status

Age, sex, years of education, MRI lesions, current smoking, and cholesterol-lowering and antihypertensive treatment

Adjusting for age, sex and education

Sex, education, history of stroke and cardiovascular risk factors

Age, educational level, depressive symptomatology, systolic blood pressure, body mass index, and tobacco and alcohol consumption 
TABLE 1 | Continued

\begin{tabular}{lllll}
\hline $\begin{array}{l}\text { Author, journal, year } \\
\text { study }\end{array}$ & $\begin{array}{l}\text { Population size } \\
\text { and age }\end{array}$ & Measurements & $\begin{array}{l}\text { Observation } \\
\text { time }\end{array}$ & Outcome \\
\hline $\begin{array}{l}\text { Suemoto, } \\
\text { Aterosclerosis 2015, }\end{array}$ & $\begin{array}{l}\text { N 8,208, Mean } \\
\text { age 49.6 }\end{array}$ & cclMT & $\begin{array}{l}\text { Cross-sectional } \\
\text { study }\end{array}$ & $\begin{array}{l}\text { cClMT: associated with worse } \\
\text { performance on the delayed word } \\
\text { ELSA-Brasil }\end{array}$ \\
& & & $\begin{array}{l}\text { recall }(\mathrm{DWRT})[\beta=-0.433,(95 \% \mathrm{Cl}= \\
-0.724 ;-0.142)] .\end{array}$
\end{tabular}

Zeki Al Hazzouri, Stroke 2015. Coronary Artery Risk Development in Young Adults study

Del Brutto, J Stroke Cerebrovasc Dis. 2020, The Atahualpa project Xiang, J Clin Neurosci, 2013

$\begin{array}{lll}\begin{array}{l}\text { N 2,618, mean } \\ \text { age 45.3 years }\end{array} & \text { IMT } & \begin{array}{l}\text { Cross sectional. } \\ \text { UL at baseline, } \\ \text { cognitive test 5 } \\ \text { years later } \\ \text { N } 561\end{array} \\ \text { cross-sectional } \\ \text { IMT 2,015 } & \begin{array}{l}\text { IMT, plaques and } \\ \text { stenosis }\end{array} & \text { Cross sectional }\end{array}$

IMT: negatively associated with processing speed [-0.06; $(95 \% \mathrm{Cl}$ -0.09 to -0.02$)]$

No association

IMT: OR 1.96 [95\% Cl 1.23-3.16] and hyperdense plaque OR $4.72[95 \% \mathrm{Cl}$ 2.56-11.2] were associated with poor cognitive performance. Patients with severe $(\geq 70 \%)$ carotid artery stenosis had a lower Mini-Mental State Examination score compared with the mild to modest (40-70\%) carotid artery stenosis group. Cognitive performance differed between patients with left and right carotid artery stenosis.
Adjusted for

Age, sex, race, marital status, income, education, cardiovascular risk factors, self-reported heart failure, alcohol use, thyroid function and depression

Age, sex, race, education, glomerular filtration rate and cardiovascular risk factors

Age and education

Age, sex, education, cardiovascular risk factors

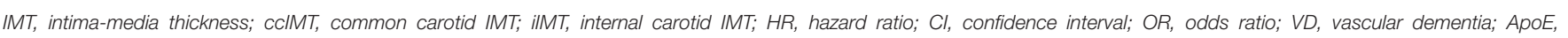
Apolipoprotein E.

be excluded. A major limitation of the available evidence is the absence of a universal understanding of how to define and assess subclinical atherosclerosis. Measurement of increased IMT, which is thought to represent the first structural change in the atherosclerotic process, is affected by the exact timing of measurement (varies throughout a cardiac cycle), the location of measurement, and the software algorithm used. Carotid plaques which are more strongly associated with traditional cardiovascular risk factors (3) and proven to be a better predictor of a future cardiovascular event, are highly age-dependent, with a lower prevalence in younger populations (3). Plaque detection rate is also affected by the resolution of the ultrasound devices. As most of the studies were conducted in the ' 90 s with older ultrasound devices, an underestimation of plaque occurrence is likely. Furthermore, the definition of plaque is not consistent between the different studies.

As with the assessment of atherosclerosis, evaluation and definition of cognitive impairment lack standardization. The use of different cognitive test batteries, and the definition of cognitive impairment across studies makes it difficult to draw clear conclusions. There are conflicting findings regarding which cognitive domains that are most vulnerable to atherosclerotic carotid disease. In general, vascular cognitive impairment is typically characterized by reduced speed of information processing, complex attention, and frontal-executive functioning (40). However, it seems likely that vascular disease contributes to the cascade of neurodegeneration (2), also affecting other cognitive domains.

\section{FUTURE PERSPECTIVES}

Despite associations between atherosclerosis and cognitive function seen in many populations, the amount of atherosclerosis required to pose a risk of cognitive impairment is unclear and is likely both age and person dependent.

Ultrasound of the carotid arteries is a cheap and noninvasive and technique to quantify atherosclerotic burden. Future studies should use standardized imaging protocols, standard definitions of atherosclerosis, and predefined outcome measures. Whether subclinical atherosclerosis poses different risk at different ages and whether different locations, and or intensifying risk factor management can contribute to halting further cognitive impairment needs further exploration.

\section{CONCLUSION}

Subclinical carotid artery atherosclerosis provides additional information about vascular risk factors burden in realtion to cognitive performance. More research is needed to address whether the assessment of carotid artery atherosclerosis could be used to identify people at increased risk of cognitive impairment and justify intensified risk factor management.

\section{AUTHOR CONTRIBUTIONS}

All authors listed have made a substantial, direct and intellectual contribution to the work, and approved it for publication. 


\section{REFERENCES}

1. World Health Organization. Towards a Dementia Plan: A WHO Guide. (2018). http://apps.who.int/iris/bitstream/handle/10665/272642/ 9789241514132-eng.pdf?ua=1 (accessed August 30, 2018).

2. Gorelick PB, Scuteri A, Black SE, DeCarli C, Greenberg SM, Iadecola $\mathrm{C}$, et al. Vascular contributions to cognitive impairment and dementia a statement for healthcare professionals from the American heart association/American stroke association. Stroke. (2011) 42:2672-713. doi: 10.1161/STR.0b013e3182299496

3. Ihle-Hansen H, Vigen T, Ihle-Hansen H, Ronning OM, Berge T, Thommessen $\mathrm{B}$, et al. Prevalence of carotid plaque in a 63- to 65-year-old norwegian cohort from the general population: the ACE (Akershus Cardiac Examination) 1950 study. J Am Heart Assoc. (2018) 7:e008562. doi: 10.1161/JAHA.118.008562

4. Viswanathan A, Rocca WA, Tzourio C. Vascular risk factors and dementia: how to move forward? Neurology. (2009) 72:368-74. doi: 10.1212/01.wnl.0000341271.90478.8e

5. Yew B, Nation DA. Cerebrovascular resistance: effects on cognitive decline, cortical atrophy, and progression to dementia. Brain J Neurol. (2017) 140:1987-2001. doi: 10.1093/brain/awx112

6. Stoll G, Bendszus M. Inflammation and atherosclerosis: novel insights into plaque formation and destabilization. Stroke. (2006) 37:1923-32. doi: $10.1161 / 01 . S T R .0000226901 .34927 .10$

7. Abrams J. Clinical practice. Chronic stable angina. New Eng J Med. (2005) 352:2524-33. doi: 10.1056/NEJMcp042317

8. Hansson GK. Inflammation, atherosclerosis, and coronary artery disease. New Eng J Med. (2005) 352:1685-95. doi: 10.1056/NEJMra043430

9. Newman AB, Fitzpatrick AL, Lopez O, Jackson S, Lyketsos C, Jagust W, et al. Dementia and Alzheimer's disease incidence in relationship to cardiovascular disease in the cardiovascular health study cohort. J Am Geriatr Soc. (2005) 53:1101-7. doi: 10.1111/j.1532-5415.2005.53360.x

10. Johnston SC, O'Meara ES, Manolio TA, Lefkowitz D, O'Leary $\mathrm{DH}$, Goldstein $\mathrm{S}$, et al. Cognitive impairment and decline are associated with carotid artery disease in patients without clinically evident cerebrovascular disease. Ann Intern Med. (2004) 140:237-47. doi: 10.7326/0003-4819-140-4-200402170-00005

11. Craven T, Ryu J, Espeland M, Kahl F, McKinney W, Toole J, et al. Evaluation of the associations between carotid artery atherosclerosis and coronary artery stenosis. A case-control study. Circulation. (1990) 82:1230-42. doi: 10.1161/01.CIR.82.4.1230

12. Bakker FC, Klijn CJ, Jennekens-Schinkel A, Kappelle LJ. Cognitive disorders in patients with occlusive disease of the carotid artery: a systematic review of the literature. J Neurol. (2000) 247:669-76. doi: 10.1007/s004150070108

13. Gustavsson AM, van Westen D, Stomrud E, Engström G, Nägga K, Hansson O. Midlife atherosclerosis and development of Alzheimer or vascular dementia. Ann Neurol. (2020) 87:52-62. doi: 10.1002/ana.25645

14. Zhong W, Cruickshanks KJ, Huang GH, Klein BE, Klein R, Nieto FJ, et al. Carotid atherosclerosis and cognitive function in midlife: the beaver dam offspring study. Atherosclerosis. (2011) 219:330-3. doi: 10.1016/j.atherosclerosis.2011.07.013

15. Mathiesen EB, Waterloo K, Joakimsen O, Bakke SJ, Jacobsen EA, Bønaa $\mathrm{KH}$. Reduced neuropsychological test performance in asymptomatic carotid stenosis: the troms $\emptyset$ study. Neurology. (2004) 62:695-701. doi: 10.1212/01.WNL.0000113759.80877.1F

16. Xiang J, Zhang T, Yang QW, Liu J, Chen Y, Cui M, et al. Carotid artery atherosclerosis is correlated with cognitive impairment in an elderly urban Chinese non-stroke population. J Clin Neurosci. (2013) 20:1571-5. doi: 10.1016/j.jocn.2013.02.026

17. Del Brutto OH, Mera RM, Recalde BY, Del Brutto VJ. Carotid intima-media thickness, cognitive performance and cognitive decline in stroke-free middleaged and older adults. The atahualpa project. J Stroke And Cerebrovasc Dis. (2020) 29:104576. doi: 10.1016/j.jstrokecerebrovasdis.2019.104576

18. Zeki Al Hazzouri A, Vittinghoff E, Sidney S, Reis JP, Jacobs Jr DR, et al. Intimamedia thickness and cognitive function in stroke-free middle-aged adults: findings from the coronary artery risk development in young adults study. Stroke. (2015) 46:2190-6. doi: 10.1161/STROKEAHA.115.008994

19. Suemoto CK, Santos IS, Bittencourt MS, Pereira AC, Goulart AC, Rundek $\mathrm{T}$, et al. Subclinical carotid artery atherosclerosis and performance on cognitive tests in middle-aged adults: Baseline results from the ELSABrasil. Atherosclerosis. (2015) 243:510-5. doi: 10.1016/j.atherosclerosis.2015. 10.008

20. Auperin A, Berr C, Bonithon-Kopp C, Touboul PJ, Ruelland I, Ducimetiere $\mathrm{P}$, et al. Ultrasonographic assessment of carotid wall characteristics and cognitive functions in a community sample of 59- to 71-year-olds. The EVA Study Group. Stroke. (1996) 27:1290-5. doi: 10.1161/01.STR. 27.8.1290

21. Ihle-Hansen $H$, Vigen $T$, Berge $T$, Hagberg G, Engedal K, Ronning $\mathrm{OM}$, et al. Carotid atherosclerosis and cognitive function in a general population aged 63-65 years: data from the akershus cardiac examination (ACE) 1950 study. J Alzheimers Dis. (2019) 70:1041-9. doi: 10.3233/ JAD-190327

22. Suemoto CK, Nitrini R, Grinberg LT, Ferretti RE, Farfel JM, Leite $\mathrm{RE}$, et al. Atherosclerosis and dementia: a cross-sectional study with pathological analysis of the carotid arteries. Stroke. (2011) 42:3614-5. doi: 10.1161/STROKEAHA.111.628156

23. Wendell CR, Zonderman AB, Metter EJ, Najjar SS, Waldstein SR. Carotid intimal medial thickness predicts cognitive decline among adults without clinical vascular disease. Stroke. (2009) 40:3180-5. doi: 10.1161/STROKEAHA.109.557280

24. Gardener H, Caunca MR, Dong C, Cheung YK, Elkind MSV, Sacco RL, et al. Ultrasound markers of carotid atherosclerosis and cognition: the northern manhattan study. Stroke. (2017) 48:1855-61. doi: 10.1161/STROKEAHA.117.016921

25. Zhong W, Cruickshanks KJ, Schubert CR, Acher CW, Carlsson CM, Klein $\mathrm{BE}$, et al. Carotid atherosclerosis and 10-year changes in cognitive function. Atherosclerosis. (2012) 224:506-10. doi: 10.1016/j.atherosclerosis.2012.07.024

26. Moon JH, Lim S, Han JW, Kim KM, Choi SH, Park KS, et al. Carotid intima-media thickness is associated with the progression of cognitive impairment in older adults. Stroke. (2015) 46:1024-30. doi: 10.1161/STROKEAHA.114.008170

27. van Oijen M, de Jong FJ, Witteman JC, Hofman A, Koudstaal PJ, Breteler MM. Atherosclerosis and risk for dementia. Ann Neurol. (2007) 61:403-10. doi: 10.1002/ana.21073

28. Sander K, Bickel H, Förstl H, Etgen T, Briesenick C, Poppert H, et al. Carotid- intima media thickness is independently associated with cognitive decline. The INVADE study. Int J Geriatr Psychiatry. (2010) 25:389-94. doi: 10.1002/gps.2351

29. Komulainen P, Kivipelto M, Lakka TA, Hassinen M, Helkala EL, Patja K, et al. Carotid intima-media thickness and cognitive function in elderly women: a population-based study. Neuroepidemiology. (2007) 28:207-13. doi: $10.1159 / 000108112$

30. Lin HF, Huang LC, Chen CK, Juo SH, Chen CS. Carotid atherosclerosis among middle-aged individuals predicts cognition: a 10-year follow-up study. Atherosclerosis. (2020) 314:27-32. doi: 10.1016/j.atherosclerosis.2020.10.015

31. Carcaillon L, Plichart M, Zureik M, Rouaud O, Majed B, Ritchie K, et al. Carotid plaque as a predictor of dementia in older adults: the three-city study. Alzheimers Dement. (2015) 11:239-48. doi: 10.1016/j.jalz.2014.07.160

32. Romero JR, Beiser A, Seshadri S, Benjamin EJ, Polak JF, Vasan RS, et al. Carotid artery atherosclerosis, MRI indices of brain ischemia, aging, and cognitive impairment: the Framingham study. Stroke. (2009) 40:1590-6. doi: 10.1161/STROKEAHA.108.535245

33. Arntzen KA, Schirmer H, Johnsen SH, Wilsgaard T, Mathiesen EB. Carotid atherosclerosis predicts lower cognitive test results: a 7-year follow-up study of 4,371 stroke-free subjects - the Tromso study. Cerebrovasc Dis. (2012) 33:159-65. doi: 10.1159/000334182

34. Knopman D, Boland LL, Mosley T, Howard G, Liao D, Szklo M, et al. Cardiovascular risk factors and cognitive decline in middle-aged adults. Neurology. (2001) 56:42-8. doi: 10.1212/WNL.56.1.42

35. Wendell CR, Waldstein SR, Ferrucci L, O'Brien RJ, Strait JB, Zonderman AB. Carotid atherosclerosis and prospective risk of dementia. Stroke. (2012) 43:3319-24. doi: 10.1161/STROKEAHA.112.672527

36. Rossetti HC, Weiner M, Hynan LS, Cullum CM, Khera A, Lacritz LH. Subclinical atherosclerosis and subsequent cognitive function. Atherosclerosis. (2015) 241:36-41. doi: 10.1016/j.atherosclerosis.2015.04.813

37. Poggesi A, Pasi M, Pescini F, Pantoni L, Inzitari D. Circulating biologic markers of endothelial dysfunction in cerebral small vessel disease: a 
review. J Cerebr Blood Flow Metab. (2016) 36:72-94. doi: 10.1038/jcbfm. 2015.116

38. de la Torre JC. Is Alzheimer's disease a neurodegenerative or a vascular disorder? Data, dogma, and dialectics. Lancet Neurol. (2004) 3:184-90. doi: 10.1016/S1474-4422(04)00683-0

39. O'Rourke MF, Safar ME. Relationship between aortic stiffening and microvascular disease in brain and kidney: cause and logic of therapy. Hypertension. (2005) 46:200-4. doi: 10.1161/01.HYP.0000168052.00426.65

40. World Health Organization. International Classification of Diseases for Mortality and Morbidity Statistics (11th Revision) (2018). Available online at: https://icd.who.int/browse11/1-m/en (accessed April 24, 2021).

Conflict of Interest: The authors declare that the research was conducted in the absence of any commercial or financial relationships that could be construed as a potential conflict of interest.
Publisher's Note: All claims expressed in this article are solely those of the authors and do not necessarily represent those of their affiliated organizations, or those of the publisher, the editors and the reviewers. Any product that may be evaluated in this article, or claim that may be made by its manufacturer, is not guaranteed or endorsed by the publisher.

Copyright (C) 2021 Ihle-Hansen, Ihle-Hansen, Sandset and Hagberg. This is an open-access article distributed under the terms of the Creative Commons Attribution License (CC BY). The use, distribution or reproduction in other forums is permitted, provided the original author(s) and the copyright owner(s) are credited and that the original publication in this journal is cited, in accordance with accepted academic practice. No use, distribution or reproduction is permitted which does not comply with these terms. 